\title{
NOTAS DE UMA PEDAGOGIA DA SINGULARIDADE ${ }^{1}$
}

\author{
Notes for a pedagogy of singularity
}

\section{Note di una pedagogia della singolarità}

Germano Nogueira Prado*

Resumo: O trabalho procura pensar uma pedagogia da singularidade. Ele consta de quatro seções e um adendo. A primeira seção caracteriza o modelo escolar de educação partindo dos conceitos de transmissão, desigualdade e controle e indicando como aí a "universalidade abstrata" do saber não coaduna com uma educação que se quer democrática. A segunda começa com a ideia (comum) de democracia como "governo de todos" e passa pela compreensão do poder nesse regime como de todos e de ninguém (como lugar de qualquer $u m$ ) para chegar à ideia de singularidade. A terceira descreve da singularidade como fundamento e sentido da democracia. A quarta extrai algumas consequências da ideia de singularidade para a educação, opondo simetricamente comunidade a transmissão, igualdade a desigualdade, risco a controle, "universalidade concreta" do pensamento a "universalidade abstrata" do saber. O adendo esboça a aplicação de uma pedagogia da singularidade nos limites da (sala de) aula.

Palavras-chave: Pedagogia. Singularidade. Democracia.

1 Devo às minhas aulas no Ensino Médio (em especial no Pedro II) e aos anos de universidade a experiência (de pensamento) no horizonte do qual o presente trabalho, ainda tateante, se tornou possível; e devo ao Círculo de Estudos da Ideia e da Ideologia (CEII) e ao Núcleo Pró-Federação Libertária de Educação (FLE) o pensamento (experimental) em que tal trabalho se enraíza - a ponto de arriscar dizer que, a rigor, trata-se de um trabalho (do) coletivo ou, antes, um trabalho (do/em) comum, como, por sinal, talvez seja qualquer obra que se preze. Last but not least, devo a Camila Prado, professora da Universidade Federal do Cariri (UFCA), a ocasião de (experimentar) pensar um texto em que aquela experiência e este pensamento se articulassem, ao me confiar uma fala na V Semana de Filosofia e seu Ensino da UFCA. Denken ist Danken.

* Doutor em Filosofia pela Universidade Federal do Rio de Janeiro (UFRJ). Professor do Colégio Pedro II. E-mail: echtnussbaum@yahoo.com.br. 


\begin{abstract}
The work aims to think a singularity's pedagogy. It has four sections and one addendum. The first section does a synthetic characterization of the traditional model of education from the concepts of transmission, inequality and control, indicating how the "abstract universality" of knowledge doesn't go with an education that wants to be democratic. The second begins with the (common) idea of democracy as "government of everybody" and pass through the comprehension of the power in a democratic regime as of everybody and nobody (as place of any- and everyone) to arrive at the singularity's idea. The third describes the singularity as ground and sense of democracy. The fourth extracts some consequences from the idea of singularity for the education, opposing community to transmission, equality to inequality, risk to control, "concrete universality" of thought to "abstract universality" of knowledge. The addendum sketches the application of singularity's pedagogy in the class(room)'s limits.
\end{abstract}

Keywords: Pedagogy. Singularity. Democracy.

Sommario: Il lavoro cerca di pensare una pedagogia della singolarità. Esso c'è quattro sezioni ed un'appendice. La prima sezione caratterizza il modello di educazione della scuola partendo dai concetti di transmissione, disuguaglianza e controllo e indicando come 1" "universalità astratta" del sapere presente lì non si accorda con un'educazione che vuol esser democratica. La seconda inizia con l'idea (comune) di democrazia come "governo di tutti" e passando attraverso la comprensione del potere in questo regime come di tutti e di nessuno (como il luogo di qualunque) giunge all'idea di singolarità. La terza descrive la singolarità come fondamento e senso della democrazia. La quarta trae alcune consequenze dell'idea di singolarità per l'educazione, opponendo simmetricamente communità a transmissione, uguaglianza a disuguaglianza, rischio a controllo, "universalità concreta" del pensiero a "universalità astratta" del sapere. L'appendice abbozza un'applicazione di una pedagogia della singolarità nei limiti dell'aula.

Parole chiavi: Pedagogia. Singolarità. Democrazia. 
A certa altura do Banquete de Platão, Sócrates, convidado a acomodarse ao lado de Agaton, o poeta por quem e a quem se dá o evento que nomeia o diálogo, diz o seguinte: "Como seria bom, Agaton, se o saber (sophia) fluísse do mais pleno ao mais carente quando estamos juntos, à maneira da água que escorre do copo mais cheio ao mais vazio através do fio de lã" (175d).

A hipótese e a imagem presentes nessa passagem ou, antes, uma determinada compreensão desta e daquela sustenta uma concepção comum e corrente de educação. Tal concepção parece ser tão antiga quanto as críticas que a cercam, com maior ou menor razão. Com efeito, visto desde o contexto mais amplo do diálogo e da obra de Platão, a fala de Sócrates pode muito bem ser incluída como um episódio da crítica (platônica) a essa imagem da educação, ao menos na medida em que o "se" que a encabeça parece conter um "mas (infelizmente?) não é assim". ${ }^{2}$

Aqui, mais do que acrescentar outra crítica a essa longa série, meu propósito é me servir (1) de uma breve caracterização - antes, de uma breve caricatura $^{3}$ - desse modelo de educação e (2) de sua crítica a partir d(e um)a ideia de democracia, para então (4) tratar de dois ou três aspectos do que poderia ser chamado de uma pedagogia da singularidade.

2 Vide o discurso de Diotima no Banquete (201d ss.) e o livro VII da República (a educação como recondução do sentido do olhar, o que supõe uma revolução (no sentido astronômico, mas não só) da alma, sob os auspícios (ou não?) de um guia (518d ss.).

3 Caricatura não é entendida aqui como mera deturpação, mas sim de acordo com a teoria gilvânica (i.e., exposta pelo prof. Gilvan Fogel em suas aulas), a partir d'O riso, de Bergson. Segundo essa teoria, por caricatura entende-se a ideia de uma descrição que procura seguir o exemplo do caricaturista, que não inventa ou deforma, mas se limita a desenvolver, para torná-lo(s) nítido(s) e visível(eis), o(s) traço(s) que só não foi (foram) exagerado(s) por Deus por conta da intervenção de um anjo bom. Não obstante, esses traços ficam ali insinuados na coisa, à espera do caricaturista, esse "anjo mal" que é capaz de ver e tornar visível esses traços. Numa boa caricatura, o resultado é um desenho que revela algo de muito próprio à coisa, sendo mais parecido com esta do que grande parte das fotografias. Nas palavras de Bergson: "A caricatura, que tem algo de diabólico, ressalta o demônio que venceu o anjo. Trata-se sem dúvida de uma arte que exagera, e, no entanto, definimo-la muito mal ao lhe atribuirmos por objetivo uma exageração, porque existem caricaturas mais verossímeis que retratos, caricaturas que mal se percebem, e inversamente podemos exagerar ao extremo sem obter um verdadeiro efeito de caricatura. Para parecer cômico, é preciso que o exagero não pareça ser o objetivo, mas simples meio de que se vale o desenhista para tornar manifestas aos nossos olhos as contorções que ele percebe se insinuarem na natureza" (BERGSON, 1983, p. 22). 
Para isso, será preciso, antes, (3) trocar três ou quatro palavras sobre a noção mesma de singularidade.

1. Em linhas bem gerais, é possível caracterizar (ou "caricatur(iz)ar") o modelo comum e corrente de educação a partir de três noções: desigualdade, transmissão, controle. De fato, o ponto de partida da situação didática básica parece ser a suposição de uma desigualdade entre os dois polos que a compõem: o professor e o aluno. O professor é representado como aquele que detém um determinado saber e o aluno, como o que não o detém. É essa desigualdade de saberes que fundaria (e/ou justificaria), em primeiro lugar, a relação entre os dois.

Mas não só. Pois é preciso, ainda, se não a vontade, a necessidade, da parte do professor, de transmitir esse saber a quem não tem - assim como, da parte do aluno, a necessidade, se não a vontade, de receber isso que the é transmitido. Ao lado da desigualdade e fundado sobre ela, está a relação de transmissão do saber.

O vetor dessa relação vai primordialmente do professor ao aluno. Com efeito, trata-se de comunicar o conteúdo do que tem ao que não tem - como a água no fio de Sócrates. Mas há aqui uma diferença fundamental: o vaso que comunica o líquido pelo fio o perde para o outro vaso, no ato mesmo da comunicação; já o professor não se esvazia do saber quando o verte ao aluno. Há quem diga que, nesse último caso, se dá até mesmo o inverso: quanto mais saber um mestre comunica (ou quanto mais vezes comunica o sabido) mais ele o tem (ou mais seguro ele é do que tem).

Assim, não obstante se funde na desigualdade, a transmissão é uma relação que vai no sentido inverso daquela. Pois trata-se de, pela comunicação de conteúdos, ou bem mitigar a desigualdade (o que se daria no chamado "nível básico do ensino") ou bem extingui-la (o que aconteceria no (sintomaticamente) denominado "Ensino Superior"). Neste último caso, o aluno, se não vem a ser ele mesmo professor, alcança o mesmo nível deste em termos de conteúdo de ser - como vasos comunicantes cujo nível de líquido se equivale.

Fundada na desigualdade (de saberes) e na transmissão (de conteúdos), aparece uma terceira característica da pedagogia predominante: o controle. Trata-se de um conjunto de procedimentos que visa assegurar a transmissão do saber. Nisso, assegura-se também a manutenção, no interior do processo de ensino-aprendizagem, da desigualdade. 
O controle se manifesta em uma série de protocolos didáticos e institucionais, que predefinem e/ou orientam a função e o lugar do professor e do aluno. Ao professor, cabe transmitir o conteúdo. Do ponto de vista didático, isso significa que ele pode usar uma série de métodos para fins de transmissão de conteúdos: a aula expositiva (com auxílio do velho "cuspe-e-giz" ou de tecnologias mais avançadas (lousas interativas, data show, etc.)), as dinâmicas, os debates, os estudos dirigidos e trabalhos em grupo, os seminários, etc. Ao longo de todo esse processo ou, como é mais comum, ao final deste ou de uma etapa dele, é efetivada a avaliação do resultado nos alunos, em geral através de trabalhos e provas. Trata-se de calcular, de traduzir em números - ou em não menos uniformizantes e hierarquizantes "conceitos" - a eficácia (ou não) da transmissão e, se for o caso, eliminar os ruídos que impediram que ela fosse feita a contento. Tais ruídos costumam ser localizados no aluno (em alguma "incapacidade" eventual ou inerente), embora não seja (mais) tão raro localizá-lo no método de transmissão do professor ou na relação mesma professor-aluno - tanto é assim que muitas escolas e faculdades fazem avaliações no sentido inverso: o professor e a aula são avaliados pelo aluno.

Em todo o processo didático-pedagógico de transmissão e verificação (da transmissão) de conteúdos, os elementos institucionais de controle da escola se fazem presentes. Reproduzindo o que seria a estrutura do saber (científico), a escola o divide em disciplinas e atribui a cada uma o tempo que corresponderia ao seu "valor formativo", medido em função de sua capacidade (presumida) de produzir um "cidadão consciente" e/ou, o que é mais comum e cada vez se tem menos vergonha de confessar, um aluno "preparado para o vestibular" (no nível médio) ou um produto pronto para atender às necessidades do mercado de trabalho (nos níveis básico e superior) ou, o que em parte quer dizer o mesmo, o corpo dócil, economicamente rentável e politicamente domado. ${ }^{45}$

Para cada disciplina, estabelece-se na medida do possível um conteúdo idêntico a ser transmitido em quantidade idêntica para cada uma das séries nas quais os alunos são divididos, de acordo com a idade e o histórico escolar. Este último registra não só quantidade de conteúdo acumulado, medido pelo

\footnotetext{
$4 \quad$ FOUCAULT, 1987 , p. 117 ss.

5 FOUCAULT, 2011, p. 105 ss.
} 
resultado das avaliações (determinando, assim, se o indivíduo tem ou não o acúmulo requerido por uma determinada posição na hierarquia escolar), mas também os antecedentes em termos de "ruídos de transmissão" (frequência na escola, desvios de comportamento, dificuldades de aprendizagem, doenças "cognitivas" em geral), interpretados e registrados não só por professores, mas por outros profissionais da instituição escolar: inspetores, diretores, psicólogos.

Ao lado do registro do histórico de rendimento e comportamento do aluno, estão outros dispositivos de controle: os horários comuns e o controle de entrada e saída; as salas idênticas e com uma disposição padrão, sublinhando os lugares de professor e de alunos; a constante vigilância de inspetores, ao vivo ou por câmeras; a identidade externa dos uniformes; as exclusões de sala por "mau comportamento", as suspensões, as conversas com psicólogos, etc. Em linhas bem gerais, tudo isso está ordenado à eficácia da transmissão de conteúdos ligada, como vimos, à produção de um determinado tipo de indivíduo, dócil e rentável.

Implícito nesse modelo de educação está uma determinada ideia de saber. O saber seria algo de universal ou, antes, de universalmente transmissível. Colada a essa universalidade, estaria a ideia de que o saber é idêntico para todos e, nessa medida, impessoal. Assim, as peculiaridades de cada um são antes obstáculos que auxílios para a transmissão e (re)produção do saber: cabe considerá-las tão só em função da identificação homogênea pelo saber universal. Tais obstáculos costumam ser considerados ou bem contingentes e superáveis (como condições socioeconômicas, entrada tardia na escola ou mesmo determinados graus de déficit de atenção) ou bem (quase que) necessários e irremediáveis (deficiências mentais, incapacidades presumidas, etc.). Assim, a desigualdade quantitativa de conteúdos (e, não raro, a desigualdade presumida de capacidade) convive com a identidade qualitativa do saber. A esta universalidade que desconsidera o pessoal ou, antes, o singular, chamaremos de universalidade abstrata.

A aposta aqui é simples: para dizer o mínimo, o modelo de educação cuja caracterização - ou a caricatura - acabamos de esboçar não é suficiente para uma educação que se quer autenticamente democrático e, nisso, emancipatória. Tentarei mostrar em que sentido partindo d(e uma cert)a ideia comum de democracia. 
2. De acordo com a visão comum, a democracia é o "governo/poder do povo" e, como somos todos povo, é o governo/poder de todos. A história nos mostra que é perigoso compreender "povo" como um todo homogêneo e a ser conduzido por um porta-voz da sua vontade única. A emergência de regimes totalitários no século XX mostrou que isso leva à tentativa de eliminação violenta de quem aquela vontade não compreende como (devendo ser) parte do todo - os outros ou as (ditas) "minorias" (judeus, deficientes, ciganos, etc.). Por outro lado, as lutas por direitos promovidas por esses outros, esses diferentes - negros, mulheres, homossexuais etc. - contra a hegemonia de certa identidade dominante e normativa - para muitos, o homem adulto heterossexual branco (cristão ocidental) - mostraram ainda mais claramente o quanto há de violento também em sociedades (autoproclamadas) democráticas: o quanto o todo forja uma identidade que esmaga o que, em relação a esta, se mostra diferente - e o faz, sobretudo, pela privação de direitos. Nesse sentido, a luta dessas "minorias" (e deixemos de lado o quanto pode haver de discurso da identidade hegemônica nessa expressão) se estruturou, em linhas gerais, na constituição de identidades contra-hegemônicas (movimento feminista, movimento negro, movimento GLBTT) que reivindicavam a ampliação e efetivação de direitos. A esse quadro, pode-se acrescentar ainda a luta por direitos sociais e pela justiça social, que visa à inclusão daqueles que estão separados dos que são "mais iguais que os outros" por outras barreiras de diferenciação - a desigualdade social (a essa altura, à identidade de "homem branco, etc.", deveríamos acrescentar algo como "capitalista" ou "de classe média" ou "burguês" ou...).

Assim, algo fundamental vem à tona nessas lutas: o fato de que aquele "todos" da democracia é composto por inúmeras diferenças e desigualdades. E se, por um lado, é desejável que estas, as desigualdades, sejam eliminadas, sejam elas de direitos ou desigualdades socioeconômicas - é verdade que, por outro lado, a eliminação das desigualdades está a serviço justamente da promoção das ou, ao menos, do dar espaço àquelas diferenças (de sexo, de cor, de gênero, de orientação sexual, de culto, de cultura). Assim, se a democracia é mesmo o governo de todos, são esses os "todos" que, igualmente, mas em sua diferença, ${ }^{6}$ tem que ter voz no diálogo que ela é.

6 BAKUNIN, s.d. p.27. 
Mais, ainda: se é verdade que a (auto-)afirmação dos diferentes enquanto diferentes é estruturada como contra-identidade, e mesmo que este tipo de afirmação seja estrategicamente fundamental para a luta contra uma identidade hegemônica, talvez seja preciso cumprir mais um passo para além da lógica de identidade e diferença (ao menos no que se refere à diferença que se define por uma identidade constituída). E esse passo é justo o de uma "política da singularidade", no âmbito da qual faz sentido uma pedagogia da singularidade, isto é: a ideia de que, radicalmente compreendida e exercida, a democracia "serve para" criar o âmbito ou os âmbitos em que a vida de todos e de cada uma possa se realizar livremente em sua singularidade.

Nesse sentido, a ideia de democracia levaria à ideia de singularidade. Vejamos esta última ideia mais de perto.

3. O tratamento da singularidade aqui só pode ser sumário. A singularidade é o fundamento da democracia justamente porque aquilo em que todos (nós) nos encontramos é justamente a singularidade. Todos e cada um de nós é singular ou, antes, vive singularmente. Pois "singularidade" é uma propriedade não (primordialmente) de indivíduos, mas da vida ou, antes, dos âmbitos em que se dá vida: uma comunidade, um grupo de amigas, uma conversa, uma sala de aula, bem como nesse conjunto de relações consigo, com o próximo e com o diverso que cada um chama de "minha vida". Como fundamento da democracia e da vida de todos e de cada uma (a rigor, fundamento da democracia porque fundamento da vida de todos e cada um), a singularidade é o passado da democracia, na medida em que ela é aquilo que, em sua ideia, a democracia sempre já pressupõe para vir a ser (o que é).

Mas, ao mesmo tempo, a singularidade é o sentido da democracia e, nessa medida, o seu futuro. Pois ser singular é o poder ser de múltiplas maneiras de cada um, de cada âmbito em que se dá vida. Esse caráter de possibilidade é o que dá a dimensão de impossível fechamento (pleno) da vida enquanto tal e, assim, sua dimensão de "eterno" porvir. Em correspondência a isso, a democracia é ela mesma sempre porvir: nunca está acabada; é sempre, como a vida mesma pela qual ela se rege, uma tarefa, algo por cujos sentidos a cada vez respondemos, ainda que não esteja sempre (se é que está alguma vez) sujeita, como tal, à "vontade" de alguém. Os discursos que preferem "construção da democracia" e/ou "democratização" ao substantivo "democracia" talvez vislumbrem algo dessa dimensão. 
Mesmo na nossa "democracia racionada", para me apropriar de uma expressão de Marighella, ${ }^{7}$ talvez um sinal do caráter de abertura de uma democracia enraizada na singularidade possa ser visto no fato de que, ao menos quanto ao princípio, o poder é um lugar (de representação) aberto, vazio, que é de todos e de cada um, mas de ninguém desde sempre e sempre determinado (em contraste com a monarquia, por exemplo) - bem como na constatação, solidária a esta, de que um dos problemas está justo no fato de que tal princípio não tem efetividade: nas diversas sociedades, costumam ser bem determinadas as características que identificam o campo dos possíveis "representantes" de todos, à diferença dos que não podem sê-lo. E talvez o que a tão falada "crise da representação" que veio à tona nas ruas do Brasil e do mundo nos últimos tempos ${ }^{8}$ indique com clareza é que o problema não está no campo dos representantes, que deveria ser mudado, restruturado e/ou ampliado, mas no conceito mesmo de representação, na diferença (na desigualdade?) que este instaura e/ ou pressupõe no "todos" que perfaz a democracia enquanto tal, isto é, em sua ideia. Daí uma democracia direta poder ser, com pleno direito, uma democracia radical, porque fincada na raiz mesma da democracia: o fato de todos sermos igualmente (sob a condição de) singulares. Seja como for, o caráter aberto da democracia, que provém do singular e caminha para esta, o seu caráter de tarefa indica que, a rigor, ela nunca acaba de ser inventada.

A singularidade é, pois, passado e futuro, fundamento e sentido da democracia como tal, pois (1) singular é o que todos somos e cada uma de nós é e a ideia de democracia é a do poder (a possibilidade e o governo) de todos (e de cada uma); (2) a singular é aberto e a democracia enquanto tal é o cuidado para que o político seja o espaço do aberto, "para todos e para ninguém (determinado)”.

\footnotetext{
SECCO, 2013.

8 Os exemplos são abundantes: a recusa da presença de emblemas de partidos nas manifestações de 2013; o surgimento e a expansão, no bojo destas, dos mais diversos coletivos e assembleias horizontais e autogestionários; a greve dos garis e dos rodoviários no Rio de Janeiro, construídas à revelia dos sindicatos e contra a peleguice destes; a enorme abstenção nas eleições europeias de 2014, etc. E em tudo isso, a incapacidade da política partidária de produzir um emblema que "represente" as ruas, que "canalize" as suas demandas.
} 
Assim, caso se queira uma educação para a democracia (e a emancipação), essa educação deve levar em conta a singularidade. É nesse horizonte que falamos, aqui, de uma pedagogia da singularidade. Vejamos mais de perto o que isso pode significar.

4. A singularidade é o que, em sua efetivação, pode tornar cada âmbito da vida absolutamente diferente de um outro, sem que com isso este se estabeleça enquanto identidade estanque e definida desde sempre e sempre. Mas embora o sentido em que cada uma (grupo ou pessoa) é singular é a cada vez um assunto próprio e de certo modo "inefável" do um em questão, o fato mesmo da singularidade pertence a todos. Nessa medida, isto é, enquanto "princípio" da efetivação de todos e de cada uma, o ser singular é o que nos faz - e a cada âmbito da vida - iguais uns aos outros, sem que para isso tenhamos que compartilhar uma identidade estrutura nesse ou naquele predicado. À diferença do modelo corrente, fundado na desigualdade ligada a uma possível identidade quantitativa de conteúdos, uma pedagogia fundada na singularidade se basearia no princípio da igualdade. ${ }^{9}$

Não se trataria, assim, de fazer convergir, pela transmissão de saber, dois a princípio desiguais a um mesmo nível de conteúdo. Os (pelo menos) dois que, a princípio, estão em jogo na aprendizagem são igualmente singulares; podem partir, assim, não do que os separa, mas do que lhes é comum - que é não só a singularidade de cada pessoa, mas, antes, a relação mesma, singular, de educação. Ao partir da relação singular que compartilham, por cuja tarefa (de constituição) responde quem vive essa relação, temos a "relação ensino-aprendizagem" compreendida não mais como transmissão, mas como (a pressuposição de e a criação de) uma comunidade.

Como comunidade singular fundada pelo princípio da igualdade de singulares, a educação - ou, antes, o aprender - pode ser a cada vez diverso e, em todo caso, estará a cada vez exposto à tarefa de responder por e, nessa medida, decidir o seu sentido. Assim, são múltiplas e sempre imprevisíveis (e em última instância incompreensíveis ${ }^{10}$ ) as possibilidades de constitui-

9 Sobre a igualdade como princípio, como pressuposto, e não como resultado da educação (RANCIÉRE, 2002, p. 10 ss).

10 Ao menos enquanto a compreensão tem a ver com predicação. Talvez o discurso próprio à singularidade - ou um deles - seja não o predicativo, mas o narrativo. Ver abaixo, notas 11 e 12 . 
ção "concreta" do aprender. A tais possibilidades, a tal singularidade são possíveis, claro, múltiplas identidades e diferenças - mas ela(s) não se reduz(em) a estas. A singularidade se define justamente por ser o que escapa à definição e, assim, é puro possível. O seu signo talvez seja justo o poder de surpreender - o que é também a possibilidade de não surpreender (o que, dependendo do que se espera, pode ser ainda mais surpreendente...).

Assim, protocolos, métodos, procedimentos, instituições ${ }^{11}$ que pressupõem a constituição de diferenças (hierárquicas, funcionais, etc.) por meio de identidades fixas, fundadas em predicações abstratas e definitivas (o aluno é isso e faz isso e isso; o professor é aquilo e faz aquilo outro; o conteúdo é $\mathrm{x}, \mathrm{y}, \mathrm{z}$ ) e em cálculos, enfim, tudo que compõe o controle do processo de transmissão de conteúdos entre desiguais tende, se não a trabalhar contra a singularidade, ao menos a se mostrar incapaz de levá-la em conta senão "negativamente", como obstáculo a ser eliminado. A esse respeito, o mínimo se pode dizer da singularidade é que ela - para falar com Badiou - se subtrai e/ou atravessa diagonalmente os controles, crescendo nos seus interstícios como uma flor no asfalto. Isso quando não se rebela e subverte desde dentro os mecanismos de segurança, seja como sintoma nas pequenas rebeliões mais ou menos conscientes de professores ou, mais comumente, de alunos (os "desvios de comportamento" ou mesmo os "déficits de atenção", por ex.), seja como reivindicação explícita de liberdade. De um jeito ou de outro, uma pedagogia que se queira da singularidade não se conforma ao e com uma pedagogia do controle e da segurança; ao responder, a cada vez, pela tarefa de decidir o que é aprender, ela é uma pedagogia do risco ${ }^{12}$ - "risco" cujo outro nome, o nome filosófico, é pensamento.

Como o mais comum e o que nos faz iguais ou nos perfaz igualmente (não obstante a e através da possível diferença absoluta); como o que nos faz "todos", a singularidade é universal. Vimos que o saber também é universal,

11 Creio que um dos grandes problemas de uma pedagogia (e de uma política) da singularidade é: como instituir isso? É possível produzir protocolos organizativos práticos a partir de algo que, por definição, escapa à predicação? Se toda predicação supõe abstração e se toda instituição supõe predicação, o ponto é: é possível uma instituição sem abstração? Uma instituição cujo princípio, em última instância, nega ela mesma? Uma instituição, pois, cujo princípio a sabota enquanto instituição - cujo princípio é, pois, a autossabotagem?

12 GALLO, 1995. 
e o é na medida em que é impessoal, em que é constituído de juízos que definem e determinam conteúdos precisamente na medida em que abstraem do que é singular. Ora, na singularidade está em jogo justo o que há de mais "pessoal e intransferível", aquilo de que nenhum de nós pode passar sem, de que não se pode, existencialmente, em última instância, abstrair. Assim, a singularidade, por definição, jamais pode ser definida por nenhum predicado (específico, cabal). Mas ela tampouco é o Deus da teologia negativa, a quem pensamos pela negação de predicados. Ela não refuta os predicados, mas tampouco se reduz a eles; ela os atravessa e se subtrai a eles. Nesse sentido preciso, a singularidade é indiferente aos predicados a que, não obstante, ela ("generosamente") dá lugar. ${ }^{13}$

13 Essa generosidade indiferente ou essa indiferença generosa, aberta está propriamente expressa no "Madrigal Melancólico", de Manuel Bandeira, que bem poderia figurar entre as figuras da singularidade qualquer recolhidas por Agamben em A comunidade que vem, sobretudo na medida em que esta é qualquer, isto é, amável (p.11); na medida, ainda, que ela é o je ne sais quoi que, tal qual é, é, no seu ser tal-(e-)qual, causa do Amor:

"O que eu adoro em ti,

Não é a tua beleza.

A beleza, é em nós que ela existe.

A beleza é um conceito.

E a beleza é triste.

Não é triste em si,

Mas pelo que há nela de fragilidade e de incerteza.

$\mathrm{O}$ que eu adoro em ti,

Não é a tua inteligência.

Não é o teu espírito sutil,

Tão ágil, tão luminoso,

- Ave solta no céu matinal da montanha.

Nem a tua ciência

Do coração dos homens e das coisas.

$\mathrm{O}$ que eu adoro em ti,

Não é a tua graça musical,

Sucessiva e renovada a cada momento,

Graça aérea como o teu próprio pensamento,

Graça que perturba e que satisfaz.

$\mathrm{O}$ que eu adoro em ti,

Não é a mãe que já perdi. 
Ora, se o saber é constituído de predicados abstratos, determinativos e definitórios que constatam/produzem identidades e diferenças (mais ou menos estanques), ${ }^{14}$ a singularidade começa ali mesmo onde o saber acaba - ou, como dizem alguns, o singular é o que "faz furo" no saber (há quem vá mais longe e diga que esse momento do furo no saber é justamente o que se pode chamar propriamente de verdade). Que a singularidade esteja no limite - ou, mesmo, além do limite - do saber, não quer dizer que ela não pode ser pensada. Seguindo uma antiga tradição, pode-se dizer mesmo que o pensamento surge justo ali onde o saber (prévio) nos abandona, e algo nos causa espanto (espanto que é ainda maior, diz Aristóteles, quando voltamos ao (autêntico) saber desde (ess)a experiência ${ }^{15}$ ). Por sinal, o pensamento já tinha aparecido quando dissemos que a singularidade está exposta ao risco por responder por si.

No lugar do princípio da desigualdade o da igualdade; no lugar da transmissão comunidade; no lugar do controle o risco; no lugar do saber

Não é a irmã que já perdi.

E meu pai.

$\mathrm{O}$ que eu adoro em tua natureza,

Não é o profundo instinto maternal

Em teu flanco aberto como uma ferida.

Nem a tua pureza. Nem a tua impureza.

$\mathrm{O}$ que eu adoro em ti - lastima-me e consola-me!

O que eu adoro em ti, é a vida." (11 de junho 1920)

14 Daí o problemão que é "saber" que discurso pode dar conta da singularidade, que "semântica" suporta a singularidade. Aqui, eu tento me confiar a uma espécie de "descrição do como do fenômeno", do espaço mesmo que ele abre aos conteúdos, mas sem identificar-se ela mesma a conteúdos ou se diferenciar de outros fenômenos por semelhante identificação. Em outras palavras, a figura da singularidade aqui em jogo implicitamente talvez seja sobretudo a matéria. Aí talvez esteja uma insuficiência da caracterização - e o fato de que a diferença do existir seja a de que ele experimenta a singularidade como tarefa, que acontece singularmente, e não propriamente a de que ele "é" singular. Em todo caso, a "essência" de um singular não está dada pelos predicados do conceito de singularidade em geral, mas pelo como da instanciação da "forma" da singularidade. Um bom candidato para um discurso da singularidade me parece ser a narrativa enquanto existencial. Os diálogos de Platão podem ser exemplares de/quanto a isso.

15 ARISTÓTELES, I, 983a10 ss. À moda kantiana, poderíamos (algo jocosamente) dizer que, se o saber é do fenômeno, a singularidade é da ordem do nôumeno, do pensável. 
o pensamento - esses elementos delimitariam, em linhas gerais, o quadro onde buscar uma pedagogia da singularidade. Nesse sentido, esta seria uma pedagogia que se arrisca a criar uma comunidade singular de pensamento, fundada na igualdade de quem responde pelo laço de aprendizado que "dá liga" a essa comunidade. É nesse horizonte que ela procuraria, na medida do possível, contribuir para a eterna invenção da democracia - e, nisso, para a eterna invenção da vida como (bem) comum.

4.1. Dentre os muitos problemas que se pode ver no que ficou dito, um dos que pode aparecer de maneira mais imediata: "ok, tudo muito bonito (ou nem tanto), mas como aplicar isso em sala de aula?" É uma questão justa, mas não se pode tentar respondê-la de pronto sem fazer algumas considerações sobre o horizonte desde o qual ela fala, ou costuma falar. Com efeito, se ao final de uma crítica à estrutura do modelo tradicional de educação oferecêssemos um método pronto, com uma série de definições sobre como fazer e o que fazer na sala de aula, estaríamos abrindo mão, uma vez mais, do risco pelo controle.

Por outro lado, devemos tentar não cair na má compreensão oposta: em nome de uma pretensa singularidade entendida como a de mônadas não comunicantes ou de átomos isolados em seu mundo, alegar que "cada caso é um caso" e que "vale tudo", sendo ocioso pensar algo que possa servir não só para a experiência própria, mas para a “do outro". Ora, se é verdade que a singularidade nos distancia tanto quanto nos aproxima; se é verdade que ela é o que temos de mais comum (ainda que isso seja uma tarefa e não uma "determinação"), então dela não se segue (necessariamente) um isolamento - pelo contrário: ela parece prescrever se não a necessidade, ao menos a possibilidade de ter em comum, de comun-icar experiências e pensamentos (e, diga-se de passagem, nessa comunicação mesma forjar um (outro) âmbito singular da vida em comum).

Nesse sentido, arriscaria dizer que a uma pedagogia da singularidade não necessariamente é vedada a produção de métodos, nem tampouco ela está condenada a proceder ao acaso; o ponto é que ela desloca a questão. Não se trata de ou método ou acaso, mas de como, a cada vez, "localizar" a singularidade e organizar o aprender a partir desta (de cada uma das envolvidas, da mesma situação) - organização esta que pode passar por método e/ou acaso, pelo vasto campo entre os dois, ou por algo fora deles. 
O importante é o cuidado com a orientação pelo singular, orientação que prescreve antes uma tarefa de pensamento a ser cumprida como prática pedagógica do que uma fórmula "teórica" a ser aplicada na "prática". Em outras palavras, trata-se de apostar em uma não cisão entre "teoria" e "prática" (cisão na qual o pensamento costuma ser posto do lado da primeira), em uma horizontalidade em que os impasses de uma reclamam a outra e vice-versa - e o pensamento é o que circula entre as duas. ${ }^{16}$

Para tentar esclarecer a coisa - ou torná-la mais palpável e, assim, propriamente singular -, tentemos analisar dois exemplos extremos, correlatos de certa maneira ao binômio método-acaso ou, caso queiramos ser mais precisos, ao binômio "método controlado" e "método que conta com o acaso" - a saber, a aula expositiva e a aula interativa/dialógica.

Mas não sem antes outra advertência: ao aceitar semelhante caminho, aceita-se uma (outra) limitação do horizonte da pergunta que ora discutimos, a saber, o fato de que o espaço em que se desenvolverá a educação seguirá sendo a "sala de aula". Ora, uma pedagogia da singularidade terá que enfrentar as questões que envolvem a eleição e a predominância deste espaço como lugar em que costuma se concentrar o processo educacional. Seja como for, esta (ainda) é o espaço em que o tal processo costuma se dar. Nesse sentido, convém pensar nesse e a partir desse espaço, ao menos se apostamos que nele o aprender possa ter lugar; que nele há um espaço para a "ação direta" e "revolucionária"; que nele, em todo caso, se desenrolam

16 "deveríamos pensar a relação entre teoria e prática de outra forma, de uma forma "horizontal". A esse respeito, poderíamos dizer que, quando a teoria se concentra em seu próprio domínio, ela começa a se confrontar com obstáculos, com muros que a impedem de avançar. Isso nos obriga a substituí-la por um outro tipo de discurso, uma prática que nos permita passar a um domínio diferente. Graças a essa passagem, poderemos resolver um problema na teoria, retornar a teoria em outro ponto, a partir de outro lugar. Da mesma forma, quando a prática se confronta com seu limite e parece não conseguir andar para a frente, é porque se faz necessário mudar de estrutura de discurso, ou seja, fazer teoria. Maneira de operar no ponto onde as diferenças entre teoria e prática se anulam para constituir uma estrutura horizontal de contínua imbricação e de passagens incessantes de um polo a outro. Assim, poderíamos dizer com Deleuze: "a prática é um conjunto de passagens (relais) de um ponto teórico a um outro, e a teoria, uma passagem de uma prática a outra. Nenhuma teoria pode se desenvolver sem encontrar uma espécie de muro e é necessário a prática para perfurar este muro". O mesmo vale para a prática" (SAFATLE, 2010, p. ?). 
batalhas importantes da "guerrilha cotidiana" pela conquista e invenção de âmbitos de democracia e de diálogo e, nisso, de pensamento. Isso posto, vamos aos exemplos.

Por "aula expositiva" entendemos aquela aula em que a professora, se não exclusivamente, ao menos predominantemente, fala e a aluna escuta. As "aulas magistrais", tradicionais nas universidades europeias, talvez sejam um exemplo extremo desse procedimento didático: as aulas são escritas sob a forma de "palestras" pela docente e lidas (de uma cátedra) para os estudantes, que no geral se limitam a tomar notas do que foi dito. ${ }^{17}$ Todavia, não é necessário que não haja diálogo entre mestre e aluno: a nota característica fundamental aqui é, ainda que $\mathrm{x}$ alunx possa vez ou outra ter voz na aula, o vetor principal desta parte do mestre e vai em direção ax discípulx.

Pois bem, esse tipo de aula pode muito bem servir ao modelo tradicional de educação (e de fato tem servido). Com efeito, a ideia de transmissão impessoal de conteúdos pode ser posta em prática aí de maneira literal: $\mathrm{x}$ professorx verte seu saber diretamente nos ouvidos dxs alunxs, que o armazenam na sua cabeça e/ou nos seus cadernos. Os recursos técnicos que são colocados em jogo aí (do velho "cuspe-e-giz" às lousas eletrônicas) não são mais que facilitadores para uma tarefa que permanece sempre a mesma. (Por sinal, o fato de que $\mathrm{x}$ professorx - sobretudo nas aulas magistrais ou nos cursinhos pré-vestibulares - fique de pé em uma cátedra acima dxs estudantes parece a expressão física, à moda de um comentário jocoso, da disposição material necessária para que o saber seja transmitido, como o líquido pelo fio, de um recipiente a outro).

Contudo, não me parece necessário que seja assim. Em vez de umx professorx que transmite conteúdos impessoais (e, nessa medida, indiferentes a quem está em jogo na aprendizagem), é possível que a aula expositiva seja um lugar em que umx mestre pensa ou, ao menos, expõe seu pensar. Nesse caso, não se trataria da transmissão de um conteúdo em que quem o transmite não está implicado, mas um falar que procura pôr em questão aquilo mesmo de que se fala, de modo que quem está jogo no processo de aprendizado (quem fala $e$ quem escuta, que não necessariamente se confundem com professorx e alunx) esteja aí, a cada vez, implicado. Em uma lição

17 PINHEIRO, 2015 
desse tipo, x mestre, mais do que transmitir um conteúdo pronto, procura mostrar, ou mesmo encenar, de maneira exemplar, o processo mesmo do pensamento, que funda todo e qualquer saber.

"Acompanhar a aula", nesse caso, significa poder repetir em si, a seu modo próprio (e, por isso, possivelmente diferente), o mesmo processo que está ali em jogo. Assim, "acompanhar a aula" seria a tarefa comum a mestre e alunx - cabe aos dois e a cada um, a cada vez, repetir em si, de modo possivelmente diferente, o pensamento mesmo. Nesse sentido, pode ocorrer aqui um diálogo radical entre mestre e discípulx, mesmo que eles não digam uma palavra um ao outro - "radical", porque nele cada um, a sua maneira, compartilha do que está na raiz de qualquer aprendizado, a saber, o pensar.

Ora, essa repetição diferente do mesmo, esse apresentar-se de algo não pela sua definição estática mas pela proposição (problemática) de uma sua imagem, não é senão a estrutura de uma das figuras da singularidade, ${ }^{18}$ a saber, o exemplo. Este é um "caso" rigoroso de singularidade universal: trata-se de uma realização possível de um universal (exemplo é sempre exemplo de alguma coisa) que, justo por ser "uma", ser "possível" e ser "realização", por mais completa e perfeita que seja, não se reduz ao universal, mas o apresenta à distância, escapando dele esse mínimo de nada que faz com que eles não se confundam mas sejam o mesmo - apresentando-o, pois, de maneira problemática, como questão (a um exemplo sempre está ligada a questão de em que medida ele é exemplo de...).

É nesse sentido que um mestre exemplar não é quem transmite um conteúdo de há muito sabido, ou que tem uma conduta segundo certos princípios morais, ou ainda aquele que segue à risca a/uma ética profissional, mas quem deixa agir sobre si a coisa mesma de que fala e exibe isso, fazendo, pois, no sentido mais rigoroso, aquilo que diz. ${ }^{19}$ Por tudo isso, poderíamos chamar esse modo de levar a cabo uma aula expositiva (ou, mais amplamente, toda aula centrada nesse dispositivo) de didática do exemplo.

\footnotetext{
AGAMBEN, 2013, p. 17 ss.

19 Nesse sentido, apropriando-nos de Badiou, talvez pudéssemos dizer que mestre é aquele que (literalmente) dá corpo a uma Verdade (cf., entre outros, Ética: ensaio sobre a consciência do Mal. Tradução de Antônio Transito e Ari Roitman. Rio de Janeiro: RelumeDumará, 1995.). Talvez esteja aí também o lugar para interpretar a frase de Guimarães Rosa: "Mestre não é quem ensina, mas quem de repente aprende".
} 
Aposto que se cada um de nós olhar com cuidado para os mestres (ou os amigos) que tivemos poderá esbarrar com ocasiões em que uma tal didática teve lugar. Limito-me a mencionar onde ela talvez possa ser encontrada na filosofia: nas aulas de Heidegger, tal como descritas por quem assistiu suas preleções, em especial Hannah Arendt; ${ }^{20}$ na "concepção musical de curso" que parecia nortear as lições de Deleuze, cujo semblante, de início, era o de uma perfeita "aula magistral", mas cujo movimento pretendia ser o mesmo de uma música: como esta, um tal curso não se interrompe, mas precisa ser escutado em sua inteireza, em todos os seus movimentos, para ser propriamente apreciado enquanto tal. ${ }^{21} \mathrm{Ou}$ ainda, para voltar ao começo, nos diálogos de Platão, que encenam incessantemente a maestria exemplar de Sócrates (mas não apenas de Sócrates).

Vejamos agora o modelo de aula que, ao menos à primeira vista, se mostraria como o oposto do modelo expositivo: a aula interativa/dialógica. $\mathrm{O}$ vetor da aula aqui se inverteria: iria, de preferência ou em casos (não) raros exclusivamente, dx alunx ax professorx. É provável que todos já tenham participado de algo do gênero: xs alunxs em geral são colocados em círculo e x próprix professorx se coloca como "mais umx" desse círculo; estx lança um tema de discussão (normalmente polêmico ou "do momento", ou ambas as coisas) e todos têm direito a voz e opinião; ax professorx cabe mediar a discussão, concedendo a palavra a quem quer falar; por vezes, cabe a elx, ao final da aula, fazer um balanço do debate, sintetizando as opiniões apresentadas e, se for o caso, expondo as conclusões que se pode retirar daí.

Parece mais difícil fazê-lo (e concebê-lo), mas também aqui é possível imaginar uma aula cujo principal objetivo é a transmissão de um saber. A discussão pode ser conduzida de tal maneira que $\mathrm{x}$ alunx seja levado a absorver um conteúdo que x professorx pretende passar, seja nessa aula mesma, seja, como é mais comum, numa aula (expositiva) posterior ou anterior. Neste último caso, a discussão serve não raro como instrumento para mobilizar a atenção $\mathrm{dx}$ alunx para a importância do conteúdo e/ou diagnosticar o que a turma "já sabe" (quando a aula em que este é exposto vem depois da discussão) ou como instrumento para verificar a absorção adequada deste, mediante sua aplicação "prática" (quando a aula vem antes).

\footnotetext{
20 ARENDT, 2001, p. 130 ss.
}

21 PINHEIRO, 2015. 
Seja como for, uma aula desse tipo, embora mais exposta ao acaso, raramente se confia inteiramente a este, mas assegura seus resultados ao ser concebida no interior de um plano prévio maior.

Por outro lado, ao contar com a (possível) participação e a "opinião" de cada umx, a aula dialógica/interativa parece enquanto tal, em alguma medida, contar com a singularidade. Mas isso pode ser uma ilusão: não raro, as opiniões servem apenas para encastelar cada pessoa em suas idiossincrasias sempre já constituídas e prevenir o indivíduo de se expor ao que outrx como outrx (o próximo) tem a dizer. Dessa maneira, o que haveria em "comum" entre os que estão em uma aula desse tipo é sua idêntica reivindicação do direito de "ter uma opinião" - e nada mais.

Ora, a impessoalidade de um tal laço social tende a impedir a constituição (ou o vir à luz) da singularidade que parece estar em jogo aí, antes de mais nada: a singularidade da situação comum de aprendizado. Nesse sentido, me parece que a questão é procurar caminhos para que todos e cada um respondam, enquanto tais, pela constituição singular de uma comunidade de aprendizado de pensamento. Mas como fazer isso?

Vejo pelo menos dois caminhos. O primeiro deles seria o de correr o risco de estruturar o curso totalmente a partir do que xs alunxs querem - ou do que elxs querem para aquela comunidade em que caem, muitas vezes, sem querer. As aulas dialógicas seriam então usadas como uma espécie de aproximação a si de cada umx dxs participantes, de modo a tornar claro o que interessa e o que pode interessar, a cada vez, a todos - e assim ir formulando um programa de estudos e atividades por cuja peculiaridade todos e cada umx, na medida do possível, tenham que responder ou estejam dispostos a responder. Um tal projeto livre e arriscado, na medida em que conta com o querer próprio e o querer dx outrx, e gira em torno do (im)possível encontro dos dois, poderia ser chamada de uma didática do desejo.

O segundo seria o de trazer para a conversa umx terceirx, ausente, mas de modo a "incitar" a que cada umx, (a princípio) segundo o que faz, pode e quer da vida, possa falar desde elx - tendo x professorx, na medida do possível, $\mathrm{o}$ lugar de mais umx entre xs alunxs. Essx terceiro - que pode ser um texto, um filme, um quadro, etc. - seria a "coisa" comum desde a qual, a cada vez, e em torno dos testemunhos e narrativas acerca dela, o aprendizado de todos e de cada umx se estruturaria. Por se estruturar em torno de umx outrx que (sempre) falta, talvez pudéssemos chamar esse procedimento de didática da ausência. 
Mais uma vez, se cada um olhar para sua história com cuidado, apostaria que não há umx que não tenha aprendido algo seja através do desejo (dx outrx), seja através da sua ausência. O desejo, por sinal, ou uma de suas formas, está inscrito na própria palavra filosofia - sobretudo se esta se faz pelo diálogo com amigxs. E o que precisam ser xs filósofxs da tradição se não (amigxs) ausentes, a quem incessantemente dirigimos a questão (no fundo dirigida a nós mesmos): o que você quer (dizer)? Ademais, se a filosofia (ao menos na medida em que questiona explicitamente sua singularidade) começa com Platão, ela começa com uma dupla ausência, que dá o que pensar: a ausência de escritos de Sócrates e a ausência de Platão quando encena, nos seus escritos, conversas do mestre.

Não custa assinalar que esses dois caminhos didáticos não se excluem - nem tampouco excluem o aprendizado através do exemplo. ${ }^{22}$ Por certo, eles também não pretendem limitar outros tantos caminhos possíveis, que são tantos quanto os nomes próprios que existem no mundo. Além disso, no esforço (necessário) de delimitar com clareza uma possibilidade em um espaço limitado, talvez seja impossível fugir à abstração, e por certo muita coisa ficou de fora - nesse caso, sobretudo, as dificuldades e os fracassos quase que inerentes a todas essas tentativas didáticas. Por tudo isso, e muito mais, o que foi dito aqui é questionável.

Mas o fracasso e o limite não são apenas negativos: sem fracasso, sem algo que emperra no correr comum das coisas, não há pensamento; e sem limite, o pensamento não ganha uma cara própria e tende a perder-se num mar de possibilidades indiferentes. Por isso, espero que o ficou dito aqui seja questionável, sobretudo, em outro sentido: no sentido de dar o que pensar.

22 Temporalmente, uma didática do exemplo parece ter a ver com o caráter de passado da singularidade (o sendo sustentado pelo ter sido exemplar de um singular), enquanto o desejo parece temporalizar-se sobretudo a partir do futuro (o aberto do que há de vir) e a ausência, talvez, sobretudo a partir do presente (ou, antes, a abertura de passado e futuro a partir da presença do texto...; ou seria também do passado?). Por outro lado, pode ser apressado fazer esse tipo de associação, ainda mais quando a coisa aparece assim tão "encaixadinha", como que num (mini)sistema sem fundamento (suficientemente claro) no fenômeno em questão. Por demandarem um cuidado específico, a que não posso me dedicar aqui, deixo para outra ocasião o desenvolvimento dessas relações. 


\section{Referências}

AGAMBEN, Giorgio. A comunidade que vem. Tradução e notas de Cláudio Oliveira. Belo Horizonte: Autêntica, 2013.

ARENDT, Hannah; HEIDEGGER, Martin. Correspondência 1925-1975. Organização de Úrsula Ludz. Tradução de Marco Antônio Casa Nova. Rio de Janeiro: Relume Dumará, 2001.

ARISTÓTELES. Metafisica. Ensaio introdutório. Texto grego com tradução e comentário de Giovanni Reale. São Paulo: Loyola, 2002.

BADIOU, Alain. Ética: ensaio sobre a consciência do Mal. Tradução de Antônio Transito e Ari Roitman. Rio de Janeiro: Relume-Dumará, 1995.

BAKUNIN, Mikhail. A instrução integral. In: . Novos Tempos 1. São Paulo: Imaginário, s.d. p.19-37.

BERGSON, Henri. O riso: ensaio sobre a significação do cômico. Rio de Janeiro: Zahar Editores, 1983.

FOUCAULT, Michel. Vigiar e punir: nascimento da prisão. Tradução de Raquel Ramalhete. Petrópolis: Vozes, 1987.

. Microfísica do poder. Organização e tradução de Roberto Machado. 29. reimp. Rio de Janeiro: Edições Graal, 2011.

GALLO, Silvio. Pedagogia do risco. Campinas: Editora Papirus, 1995.

PINHEIRO, Ulysses. As aporias da didática em Deleuze e Spinoza. Educação e Filosofia, Uberlândia, v. 29, n. 57, p. 263-283, jan./jun. 2015.

PLATÃO. O banquete. Tradução, notas e comentários de Donaldo Schüler. Porto Alegre: L\&PM, 2010.

. La repubblica. Introduzione, traduzione e note di Mario Vegetti. 3. ed. Milano: Bur, 2010.

RANCIÉRE, Jacques. O mestre ignorante. Tradução de Lilian do Valle. Belo Horizonte: Autêntica, 2002.

SAFATLE, Vladimir. Das Cinzas. Revista Cult, São Paulo, n. 118. Disponível em: <http://revistacult.uol.com.br/home/2010/03/das-cinzas/>. Acesso em: 30 dez. 2014. 
SECCO, Lincoln. A democracia racionada. Le monde diplomatique, São Paulo, n. 108. Disponível em: <http://187.95.195.112/artigo. php?id=1545>. Acesso em: 02 jan. 2015.

Data de registro: 02/01/2015

Data de aceite: $31 / 05 / 2015$ 